\title{
Reactivation of Pulmonary Tuberculosis following Treatment of Myelofibrosis with Ruxolitinib
}

\author{
Maheen Z. Abidi, ${ }^{1}$ Javeria Haque, ${ }^{2}$ Parvathi Varma, ${ }^{3}$ Horatiu Olteanu, ${ }^{4}$ \\ Guru Subramanian Guru Murthy, ${ }^{5}$ Binod Dhakal, ${ }^{5}$ and Parameswaran Hari ${ }^{5}$ \\ ${ }^{1}$ Division of Infectious Diseases, Department of Medicine, University of Colorado, Denver, CO, USA \\ ${ }^{2}$ Division of Infectious Diseases, Department of Medicine, Medical College of Wisconsin, Milwaukee, WI, USA \\ ${ }^{3}$ University of Birmingham Medical School, Edgbaston, Birmingham, UK \\ ${ }^{4}$ Department of Pathology, Medical College of Wisconsin, Milwaukee, WI, USA \\ ${ }^{5}$ Division of Hematology and Oncology, Department of Medicine, Medical College of Wisconsin, Milwaukee, WI, USA
}

Correspondence should be addressed to Maheen Z. Abidi; maheen.abidi@ucdenver.edu

Received 8 August 2016; Revised 3 October 2016; Accepted 4 October 2016

Academic Editor: Eduardo Arellano-Rodrigo

Copyright (C) 2016 Maheen Z. Abidi et al. This is an open access article distributed under the Creative Commons Attribution License, which permits unrestricted use, distribution, and reproduction in any medium, provided the original work is properly cited.

Ruxolitinib is widely in use for treatment of myeloproliferative disorders. It causes inhibition of the Janus kinase (JAK) signal transducer and activation of transcription (STAT) pathway, which plays a key role in the underlying pathophysiology of myeloproliferative diseases. We describe a case of reactivation pulmonary tuberculosis in a retired physician while on treatment with ruxolitinib. We also review the literature on opportunistic infections following use of ruxolitinib. Our case highlights the importance of screening for latent tuberculosis in patients from highly endemic areas prior to start of therapy with ruxolitinib.

\section{Introduction}

Janus kinase (JAK) inhibitors, such as ruxolitinib(INCB018424), are being widely used for their excellent efficacy in decreasing the constitutional symptoms and splenomegaly in patients with myeloproliferative neoplasms such as primary myelofibrosis (MF) [1]. The JAK-STAT (signal inducer and activator of transcription) pathway is essential for host immunity and defense [2,3]. Clinical trials of ruxolitinib have not shown a significant increase in infectious complications [4]. However, several case reports have been published recently describing opportunistic infections in patients on treatment with ruxolitinib [5-15]. We report a case of reactivation pulmonary tuberculosis (TB) following ruxolitinib therapy.

\section{Case}

A 69-year-old male, retired physician who practiced in India was diagnosed with primary myelofibrosis in May 2015. His initial presentation included anemia with massive splenomegaly. Spleen size was evaluated by USS and measured $28 \mathrm{~cm}$ in long axis. Constitutional symptoms at diagnosis included night sweats, abdominal pain, weight loss, itching, fatigue, and early satiety. His medical history was negative for major infectious disease. Bone marrow biopsy confirmed MF, grade MF 3 [16], JAK2V617F mutation negative, MPL exon 10 mutation negative, and CALR mutation positive. This was a type 1 mutation with 52 bp deletion in exon 9 of CALR gene.

He had an intermediate 2 DIPSS plus score and was started on ruxolitinib at $20 \mathrm{mg}$ twice daily for symptom relief. He had a rapid improvement in his constitutional symptoms in the first three weeks of treatment with ruxolitinib. Prior to receipt of ruxolitinib, a screening chest X-ray was negative. Three weeks after initiation of ruxolitinib therapy, he was admitted to the hospital with high-grade fevers $\left(T_{\max } 102^{\circ} \mathrm{F}\right)$, night sweats, shortness of breath, and nonproductive cough. His physical exam revealed matted cervical lymphadenopathy and splenomegaly. QuantiFERON-TB test (Celestis, Valencia, CA) was positive. Computed tomography (CT) of 


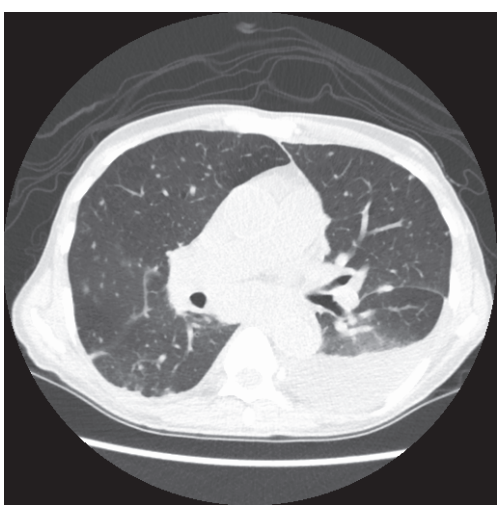

FIGURE 1: CT scan of chest showing diffuse lung nodules bilaterally, left sided effusion, and mediastinal adenopathy.

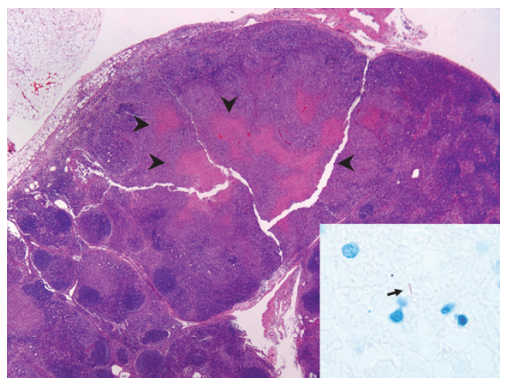

FIGURE 2: Supraclavicular lymph node (hematoxylin and eosin stain, 20x) with partially effaced architecture and necrotizing granulomatous inflammation (arrow heads). Focal extramedullary hematopoiesis was also present. The arrow in the inset indicates an acid-fast organism (AFB stain, 1,000x).

the chest showed bilateral lung nodules, left sided pleural effusion, and lower cervical and mediastinal conglomerate adenopathy (Figure 1). An excisional lymph node biopsy of a cervical node showed necrotizing granulomatous inflammation and rare acid-fast bacilli (AFB) (see Figures 2 and 3). Lymph node tissue cultures were positive for Mycobacterium tuberculosis complex by gene-probe (GenProbe, San Diego, CA). Ruxolitinib was discontinued and standard 9-month four-drug antituberculosis therapy (ATT) with rifampin, isoniazid, pyrimethamine, and ethambutol was started which led to rapid improvement in his symptoms. After 6 months of successful ATT, ruxolitinib was reintroduced for his MF symptoms, and he was continued on ATT with isoniazid and rifampin. At follow-up, he remains without transfusion needs and is symptomatically improved with minimal constitutional symptoms. There is complete resolution of lung nodules.

\section{Discussion}

The JAK-signal transducer and activator of transcription (STAT) pathway plays a critical role in host defenses and cell mediated immunity. Use of ruxolitinib in patients with myelofibrosis can cause inhibition of the JAK-STAT signaling, thus leading to depressed $\mathrm{T}$ helper cell type 1 response

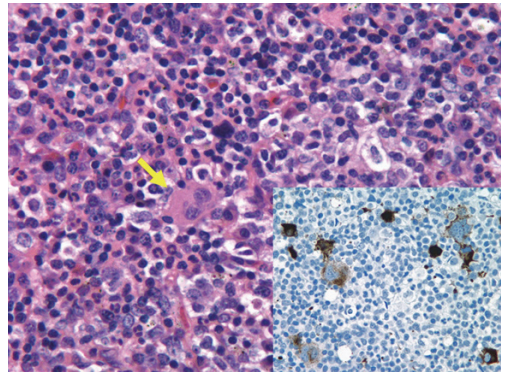

FIGURE 3: Supraclavicular lymph node (hematoxylin and eosin stain, 500x) with focal areas of extramedullary hematopoiesis, including megakaryocytes (yellow arrow). The inset (CD61 immunohistochemistry, 500x) highlights frequent atypical megakaryocytes (brown) staining positive for CD61 (a platelet and megakaryocytes marker), consistent with the underlying diagnosis of primary myelofibrosis.

and a reduction of multiple cytokine production including IFN- $\gamma$ and TNF- $\alpha$. T-Inflammatory cytokines, interferongamma (IFN- $\gamma$ ), and tumor necrosis factor- $\alpha$ (TNF- $\alpha$ ) have a critical role in prevention of reactivation and control of $\mathrm{TB}$ infection $[6,9]$. TNF- $\alpha$ plays a crucial role in T cell function, macrophage activation, and granuloma formation. This poses a threat for reactivation or dissemination of infections, particularly atypical bacterial, mycobacterial, fungal, and viral infections [17].

According to the World Health Organization, nearly onethird of the population has asymptomatic or latent tuberculosis. Less than $10 \%$ of these latent tuberculosis cases reactivate, but these cases account for nearly $80 \%$ of active tuberculosis cases. The overall incidence of tuberculosis is decreasing worldwide, but it remains a concern in patients receiving biologics such as TNF- $\alpha$ inhibitors, interleukin antagonists, and JAK inhibitors.

Eight cases of TB after ruxolitinib use in patients have been previously reported in literature (Table 1) $[5-7,9-12,18]$. Dissemination of TB was reported in five of these cases $[5,7,9,10,12]$, while the remaining two cases reported were of reactivation pulmonary TB [6] and extrapulmonary TB [11]. Therapy with ruxolitinib was withheld, and standard fourdrug ATT was given in all eight cases except one [5]. Due to a relapse of MF syndromes, ruxolitinib therapy was reinitiated with success by Palandri et al. and Hopman et al. $[9,11]$. Duration of treatment varied from 6 months [11] to 12 months in cases with disseminated TB $[5,9,12]$. At the completion of standard ATT, Palandri et al. chose to maintain long-term prophylaxis with isoniazid with no evidence of subsequent TB reactivation [11]. More recently, Branco et al. recently described a case of disseminated TB, occurring in a ruxolitinib treated patient, where ruxolitinib therapy was maintained while patient received rifampin [5].

Based on our experience, before initiating treatment with ruxolitinib, we recommend TB screening with MTB QuantiFERON test especially for patients from $\mathrm{TB}$ endemic areas or with prior history of $\mathrm{TB}$ exposure. If latent $\mathrm{TB}$ is diagnosed, treatment for latent TB per Infectious Disease Society of 
TABLE 1: Summary of cases of Mycobacterium tuberculosis after receipt of ruxolitinib described in the literature.

\begin{tabular}{|c|c|c|c|c|c|c|c|}
\hline & Case 1 & Case 2 & Case 3 & Case 4 & Case 5 & Case 6 & Case 7 \\
\hline Age $(y) / \operatorname{sex}$ & $78 / \mathrm{F}$ & $78 / \mathrm{F}$ & $72 / \mathrm{M}$ & $68 / \mathrm{M}$ & $82 / \mathrm{M}$ & $65 / \mathrm{F}$ & $62 / \mathrm{M}$ \\
\hline Infection & $\begin{array}{l}\text { Disseminated } \\
\text { TB }\end{array}$ & $\begin{array}{l}\text { Disseminated } \\
\text { TB }\end{array}$ & Miliary TB & $\begin{array}{l}\text { Pulmonary } \\
\text { TB }\end{array}$ & $\begin{array}{l}\text { Reactivated } \\
\text { pulmonary } \\
\text { TB }\end{array}$ & $\begin{array}{l}\text { Extrapulmonary } \\
\text { TB }\end{array}$ & $\begin{array}{l}\text { Disseminated } \\
\text { TB }\end{array}$ \\
\hline $\begin{array}{l}\text { Timing of infection after } \\
\text { start of ruxolitinib }\end{array}$ & 1.5 years & Unspecified & 5 months & 4 weeks & 2 months & 4 months & 7 weeks \\
\hline Treatment of infection & ATT & ATT & ATT & ATT & ATT & ATT & ATT \\
\hline $\begin{array}{l}\text { Resolution of infection } \\
\text { after treatment }\end{array}$ & & Yes & No & No & Yes & Yes & Yes \\
\hline $\begin{array}{l}\text { Ruxolitinib therapy after } \\
\text { diagnosis of infection }\end{array}$ & Continued & $\begin{array}{l}\text { Discontinued at } \\
\text { diagnosis of } \\
\text { infection }\end{array}$ & Discontinued & Discontinued & Discontinued & Discontinued & Discontinued \\
\hline $\begin{array}{l}\text { Reintroduction of } \\
\text { ruxolitinib during } \\
\text { treatment of infection }\end{array}$ & $\begin{array}{l}\text { Ruxolitinib } \\
\text { continued } \\
\text { without } \\
\text { interruption }\end{array}$ & No & No & No & No & $\begin{array}{l}\text { Restarted after } 6 \\
\text { months of ATT }\end{array}$ & Restarted \\
\hline $\begin{array}{l}\text { Ruxolitinib resumed after } \\
\text { completion of infection } \\
\text { treatment }\end{array}$ & $\begin{array}{l}\text { Continued } \\
\text { without } \\
\text { interruption }\end{array}$ & Unspecified & No & No & Unspecified & $\begin{array}{l}\text { Ruxolitinib } \\
\text { continued with } \\
\text { isoniazid } \\
\text { prophylaxis }\end{array}$ & Continued \\
\hline Relapse of infection & No & No & N/A & N/A & No & No & No \\
\hline Outcome & Alive & Alive & Died & Died & Alive & Alive & Alive \\
\hline Year/reference & $2016 /[5]$ & $2015 /[12]$ & $2015 /[10]$ & $2015 /[10]$ & $2015 /[6]$ & $2015 /[11]$ & $2014 /[9]$ \\
\hline
\end{tabular}

America guidelines should be considered before starting treatment with ruxolitinib [19].

\section{Competing Interests}

The authors have no competing interests to disclose.

\section{References}

[1] R. A. Mesa, J. Gotlib, V. Gupta et al., "Effect of ruxolitinib therapy on myelofibrosis-related symptoms and other patientreported outcomes in COMFORT-I: a randomized, doubleblind, placebo-controlled trial," Journal of Clinical Oncology, vol. 31, no. 10, pp. 1285-1292, 2013.

[2] S. Parampalli Yajnanarayana, T. Stübig, I. Cornez et al., "JAK1/2 inhibition impairs $\mathrm{T}$ cell function in vitro and in patients with myeloproliferative neoplasms," British Journal of Haematology, vol. 169, no. 6, pp. 824-833, 2015.

[3] K. Schönberg, J. Rudolph, M. Vonnahme et al., "JAK inhibition impairs NK cell function in myeloproliferative neoplasms," Cancer Research, vol. 75, no. 11, pp. 2187-2199, 2015.

[4] S. Verstovsek, H. Kantarjian, R. A. Mesa et al., "Safety and efficacy of INCB018424, a JAK1 and JAK2 inhibitor, in myelofibrosis," The New England Journal of Medicine, vol. 363, no. 12, pp. 1117-1127, 2010.

[5] B. Branco, D. Metsu, M. Dutertre et al., "Use of rifampin for treatment of disseminated tuberculosis in a patient with primary myelofibrosis on ruxolitinib," Annals of Hematology, vol. 95, no. 7, pp. 1207-1209, 2016.

[6] Y.-H. Chen, C.-H. Lee, and S.-N. Pei, "Pulmonary tuberculosis reactivation following ruxolitinib treatment in a patient with primary myelofibrosis," Leukemia \& Lymphoma, vol. 56, no. 5, pp. 1528-1529, 2015.

[7] C. Colomba, R. Rubino, L. Siracusa et al., "Disseminated tuberculosis in a patient treated with a JAK2 selective inhibitor: a case report," BMC Research Notes, vol. 5, article 552, 2012.

[8] R. A. Goldberg, E. Reichel, and L. J. Oshry, "Bilateral toxoplasmosis retinitis associated with ruxolitinib," New England Journal of Medicine, vol. 369, no. 7, pp. 681-683, 2013.

[9] R. K. Hopman, S. J. Lawrence, and S. T. Oh, "Disseminated tuberculosis associated with ruxolitinib," Leukemia, vol. 28, no. 8, pp. 1750-1751, 2014.

[10] S. Keizer, R. Gerritsen, Y. Jauw, J. Janssen, B. Koopman, and P. Bresser, "Fatal tuberculosis during treatment with ruxolitinib," Nederlands Tijdschrift voor Geneeskunde, vol. 159, no. 22, article A8650, 2015.

[11] F. Palandri, N. Polverelli, L. Catani, and N. Vianelli, "Ruxolitinib-associated tuberculosis: a case of successful ruxolitinib rechallenge," Annals of Hematology, vol. 94, no. 3, pp. 519-520, 2015.

[12] E. Shamil, D. Cunningham, B. L. Wong, and P. Jani, "Ruxolitinib associated tuberculosis presenting as a neck lump," Case Reports in Infectious Diseases, vol. 2015, Article ID 284168, 3 pages, 2015.

[13] J. von Hofsten, M. Johnsson Forsberg, and M. Zetterberg, "Cytomegalovirus retinitis in a patient who received ruxolitinib," The New England Journal of Medicine, vol. 374, no. 3, pp. 296-297, 2016.

[14] R. Wathes, S. Moule, and D. Milojkovic, "Progressive multifocal leukoencephalopathy associated with ruxolitinib," The New England Journal of Medicine, vol. 369, no. 2, pp. 197-198, 2013.

[15] N. G. Wysham, D. R. Sullivan, and G. Allada, "An opportunistic infection associated with ruxolitinib, a novel janus kinase 1,2 inhibitor," Chest, vol. 143, no. 5, pp. 1478-1479, 2013. 
[16] J. Thiele, H. M. Kvasnicka, F. Facchetti, V. Franco, J. Van Der Walt, and A. Orazi, "European consensus on grading bone marrow fibrosis and assessment of cellularity," Haematologica, vol. 90, no. 8, pp. 1128-1132, 2005.

[17] D. P. McLornan, A. A. Khan, and C. N. Harrison, "Immunological consequences of JAK inhibition: friend or foe?" Current Hematologic Malignancy Reports, vol. 10, no. 4, pp. 370-379, 2015.

[18] W. G. Dixon, K. L. Hyrich, K. D. Watson et al., "Drug-specific risk of tuberculosis in patients with rheumatoid arthritis treated with anti-TNF therapy: results from the British Society for Rheumatology Biologics Register (BSRBR)," Annals of the Rheumatic Diseases, vol. 69, no. 3, pp. 522-528, 2010.

[19] P. Nahid, S. E. Dorman, N. Alipanah et al., "Official American Thoracic Society/centers for disease control and prevention/ infectious diseases society of America clinical practice guidelines: treatment of drug-susceptible tuberculosis," Clinical Infectious Diseases, vol. 63, no. 7, pp. e147-e195, 2016. 


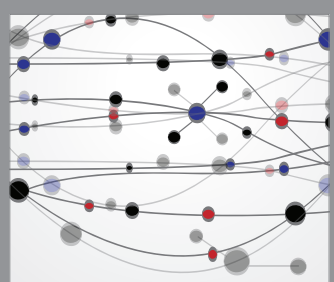

The Scientific World Journal
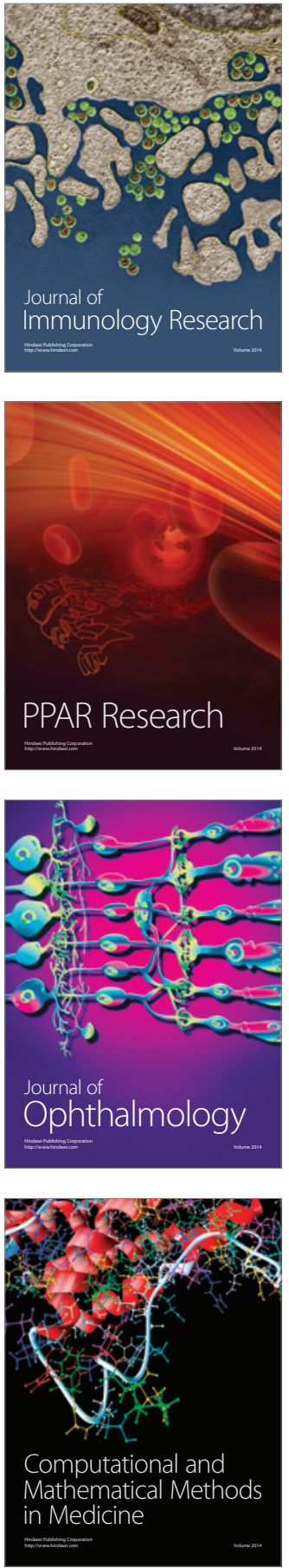

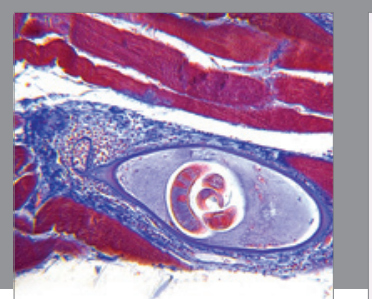

Gastroenterology Research and Practice

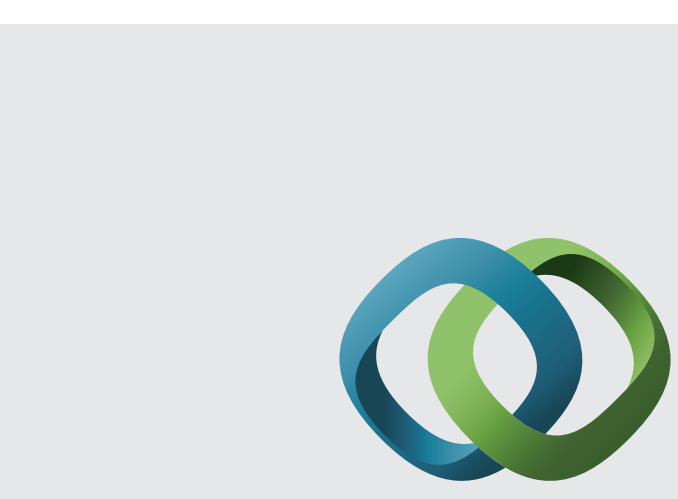

\section{Hindawi}

Submit your manuscripts at

http://www.hindawi.com
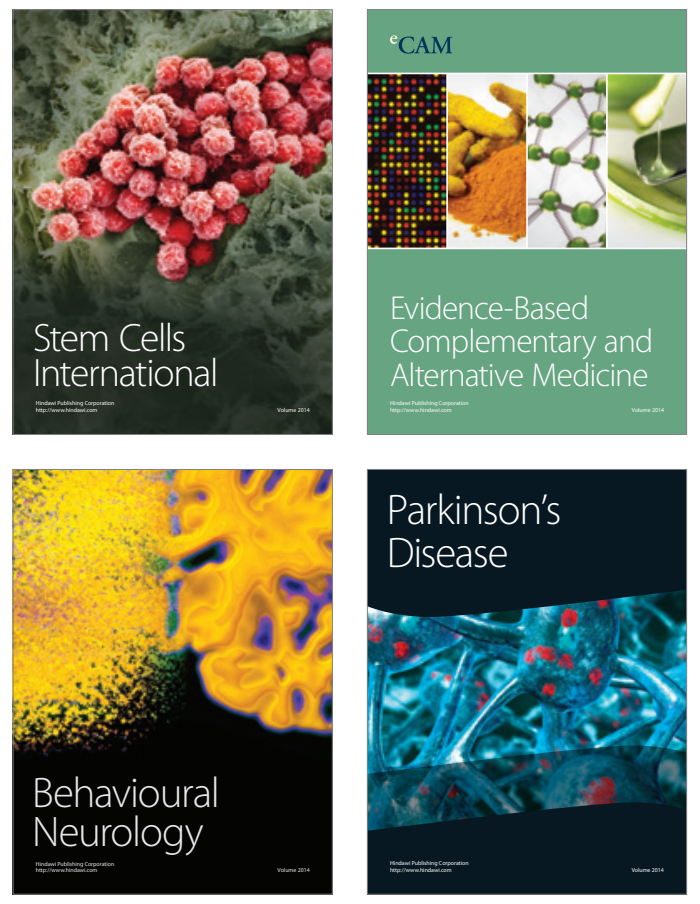
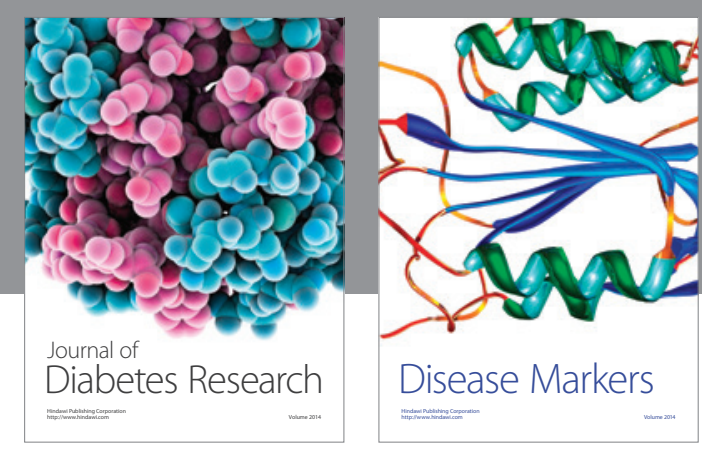

Disease Markers
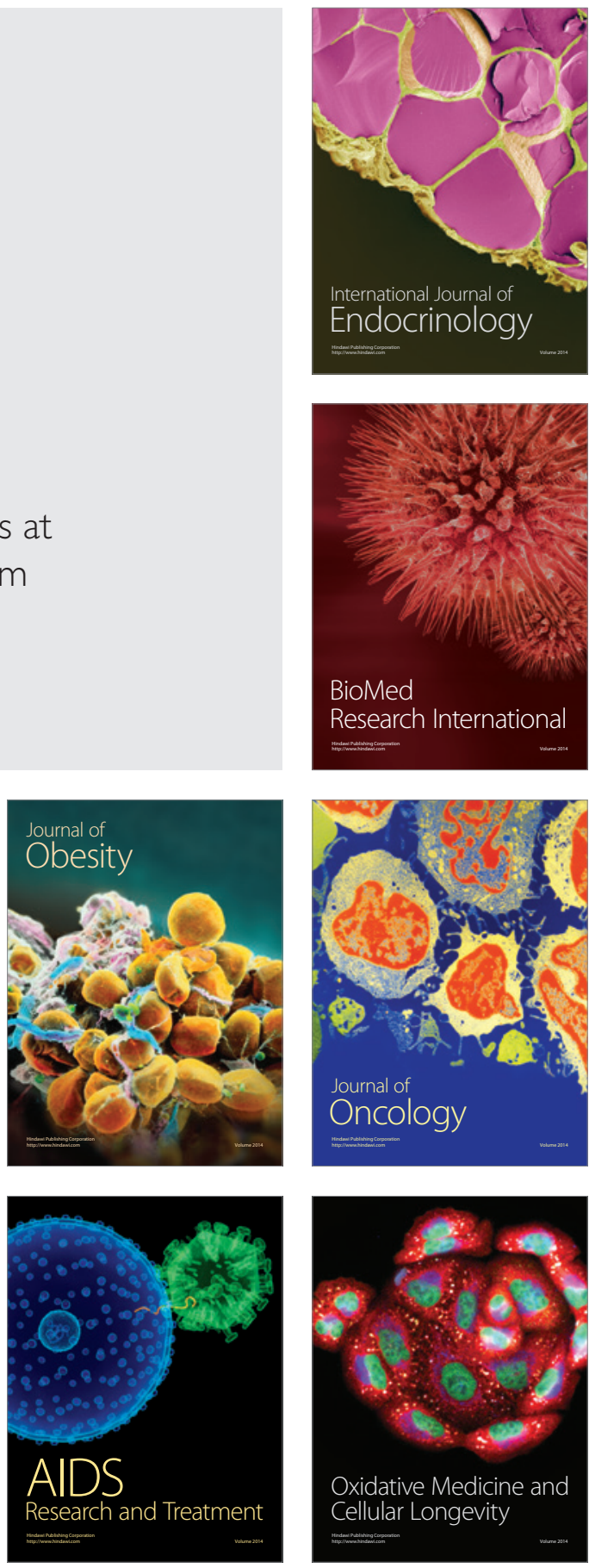